they were eventually snowed up and covered with snow. This possibility may have before been started, but seems to me to te reasonable and probable.

Athenæum, February 2

K. Busk

\section{Our Future Clocks and Watches}

IF clocks are to strike at all, surely once per hour is insufficient, while four times is excessive; the high hour-numbers even now are inconvenient to count, and with the quarters heard alone it is possible to make a mistake of an hour. I cannot but think, then, on the whole, that the necessities of ship-life have long driven mariners into the very best method, free from all difficulties, and that, whatever our way of noting hours, we could do no better than adopt the naval half-hour strikings for land-clocks, recommencing with each four-hour watch. Some confusion with the existing ways, as long as they survive, is inevitable, and equal whatever change is made.

A mistake of four hours is just as unlikely as one of twelve. We should probably soon find names for the different four-hour divisions ; for example, we might denote each half-hour by some letter or cypher. EDWARD L. GarbetT

\section{THE LIFE-HISTOR Y OF THE LYCOPODIACEAE}

THE area within which really notable discoveries are possible - at any rate amongst the higher plants-in the field of vegetable morphology is becoming very circumscribed. For some time the complete life-history of the Lycopodiacea has been a missing chapter in our text-books. Hofmeister, like others, had unsuccessfully sown the spores, and he could only speculate as to the probability of their producing-if the proper conditions could be known-a prothallium like ferns. And Spring, the monographer of the group, had hazarded the extraordinary theory that the existing representatives of the group were only represented by male plants, the females having been lost in some remote geological catastrophe.

De Bary made in this, as in so many other fields, the first real advance. He described in $185^{8}$ the early stages of the germination of the spores of Lycopodium inundatum. But just as Hofmeister had failed to get the spores to germinate at all, so De Bary failed to get the development of the prothallium to advance beyond a very early stage. Thus matters stood till 1872, when Fankhauser had the good fortune to find, in a botanical excursion, young plants of Lycopodium annotinum, still united to their parent prothallium.

For my own part, I have always felt that it might be the chance of any wide-awake observer to turn the next unread page in this curiously reserved history. And I have never failed to remind the younger botanists who have consulted me as to a promising direction for work that this was a possibility they should never lose sight of. Within the last few days, however, two fresh contributions to the subject have come into my hands.

The first number of the Botanisches Centralblatt for this year contains a paper by Bruchmann, who has, if I mistake not, already done some good work in the vegetative morphology of Lycopodium. He has had the good luck to repeat Fankhauser's happy find, and to have come across, at the end of August last, living prothallia of the same species.

But the paper ${ }^{1}$ which will mark its epoch in the history of Lycopodium is that for a separate copy of which I am indebted to my friend, Dr. Treub, the accomplished director of the renowned Botanic Garden at Buitenzorg in Java. Six years ago, when he had no thought that he would ever be able to prosecute botanical research in the tropics, he also made, as so many others have done, unsuccessful attempts to obtain the development of Lycopodium spores. On his arrival at Buitenzorg, he lost no time in endeavouring to find the prothallia of tropical species. He seems to have all but succeeded in dis${ }^{x}$ Ann. du Jardin Botanique de Buitenzorg, vol. iv. pp. ${ }^{107-138, ~ t h . ~}$ ix.-xvii. covering those of Lycopodium cernuum-but for an accidental circumstance which threw him off the scent-in the first year of his residence there. Subsequently, he sowed the spores on the trunks of trees, and after a delay which led him to abandon any hope of success, he obtained satisfactory results from one of the sowings. Now he is acquainted with the prothallia of three species of Lycopodium, and hopes to be able to describe even a fourth.

In the present paper, which is illustrated with nine admirable plates, Dr. Treub gives an exhaustive account of the prothallium of Lycopodium cernuum. It is curious to observe, however, that in artificial cultures he did not succeed in carrying the development further than De Bary had done some time ago with $L$. inundatum. Fortunately, prothallia which he discovered under spontaneous conditions of development exactly fitted in where the others stopped.

The adult prothallium is a very singular structure, consisting of a sort of short cylindrical axis, half immersed in the soil at one end, where it is furnished with roothairs. The upper extremity bears a tuft of small leaf-like lobes. The archegonia and antheridia are found on the upper part of the cylindrical axis, forming a kind of ring or crown near the tuft of lobes. The prothallium therefore presents a type morphologically more differentiated than is met with elsewhere amongst the vascular cryptogams. While this is the case with the sexual generation (oophore), the spore-bearing generation (sporophore) in its embryonic stage is less differentiated than is the case, for example, in the fern. The embryonic root is suppressed, and the whole embryo, which is wholly parenchymatous, approximates in its morphological characters to those of the prothallium.

\section{W. T. THISELTON DYER}

\section{ҰOHN GWYN $7 E F F R E Y S$}

$\mathrm{T} \mathrm{T}$ is with much regret we have to announce the death of this veteran conchologist. Dr. Gwyn Jeffreys, who was in his usual health the day before, and in the evening attended at the lecture given by his son-in-law, Prof. Moseley, at the Royal Institution, was seized on Saturday morning, January 24, with a fit of apoplexy, and at five o'clock on the same afternoon passed peacefully away. He was the last, or almost the last, of a band of marine zoologists of a former generation who had been his friends. Dilwyn, Cocks, and Couch; Fleming, Gray, Forbes, Alder, and Albany Hancock; Johnston and William Thompson; Barlee and Waller are names of the past.

Dr. Gwyn Jeffreys was born at Swansea on January 18 , I 809 , and had thus just completed his seventy-sixth year. While a boy he showed a taste for natural history, collecting the insects and shells of South Wales. When only nineteen he contributed a paper to the Linnean Transactions, "A Synopsis of the Pneumonobranchous Mollusca of Great Britain," and from that date until the present time he has been adding by his writings to our knowledge of the molluscan fauna of Europe and the North Atlantic. His most important works are : "British Conchology," in five volumes, and a series of papers (unfortunately unfinished) in the Proceedings of the Zoological Society, on "The Mollusca of the 'Lightning" and "Porcupine' Expeditions, I868-70." At the age of twenty he was elected a F.L.S., and in I840 F.R.S., and he was an honorary LL.D. of St. Andrews. He was one of the most regular members of the Royal Society Club, and took great interest in the meetings of the British Association, which he almost always attended, taking a more active part in 1848 , when Local Treasurer at the first meeting at Swansea, in 1880 , when a Vice-President at the last meeting held in the same town, and in 1877 , when President of the Biological Section. For many 